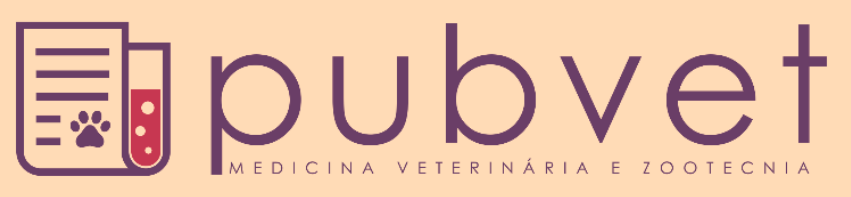

https://doi.org/10.31533/pubvet.v14n2a519.1-8

\title{
Leptospirose no contexto da Saúde Única e diretrizes de vacinação
}

\author{
Angela Ramos Silvestrini ${ }^{1 *} \bullet$, Marcos Bryan Heinemann ${ }^{2} \bullet$, Alessandra Marnie Martins Gomes \\ de Castro $^{30}$ \\ ${ }^{I}$ Mestranda do Programa de Mestrado Profissional em Saúde Ambiental das Faculdades Metropolitanas Unidas. São Paulo - SP, Brasil. \\ ${ }^{2}$ Pesquisador e Professor Associado do Departamento de Medicina Veterinária Preventiva e Saúde Animal da Faculdade de Medicina \\ Veterinária e Zootecnia da Universidade de São Paulo. São Paulo-SP, Brasil. \\ ${ }^{3}$ Pesquisadora e Docente do Curso de Medicina Veterinária e Mestrado Profissional em Saúde Ambiental das Faculdades Metropolitanas \\ Unidas. São Paulo - SP, Brasil. \\ *Autor para correspondência, E-mail: angevet@uol.com.br
}

Resumo. O conceito de Saúde Única baseia-se sobretudo na interrelação existente no trinômio saúde humana, saúde animal e meio-ambiente. Do relacionamento contemporâneo entre os seres humanos e os animais no ambiente que os circundam emergem doenças, dentre elas as zoonoses, transmitidas dos animais ao homem. Levando-se em consideração a leptospirose, uma doença zoonótica, infecciosa, febril, aguda ou crônica de etiologia bacteriana cuja propagação está associada a fatores ambientais, pretende-se discutir, contextualizar e criticar, além da necessidade de adequação da infraestrutura das cidades na sustentação do pleno relacionamento entre os seres humanos e os animais à luz da Saúde Única, medidas profiláticas como a vacinação canina contra a leptospirose, levando-se em conta as atuais diretrizes.

Palavras chave: leptospirose, vacinação canina, Saúde Única

\section{Leptospirosis in the context of One Health and vaccination guidelines}

Abstract. The One Health concept is based above all on the interrelationship in the human health, animal health and environment trinomics. From the contemporary relationship between humans and animals in the environment surrounding them we have the emergence of diseases, including zoonoses, transmitted from animals to humans. Taking into account leptospirosis, an acute or chronic febrile infectious zoonotic disease of bacterial etiology whose propagation is associated with the factors mentioned above, our intended is to discuss, contextualize and criticize, besides the need to adapt the infrastructure of the cities in the support of the full relationship between humans and animals in the context of the One Health, prophylactic measures such as canine vaccination against leptospirosis, taking into account the current guidelines.

Keywords: leptospirosis, canine vaccination, One Health

\section{Leptospirosis en el contexto de la Salud Única y pautas de vacunación}

Resumen. El concepto de Una Única Salud se basa principalmente en la interrelación entre la salud humana, la salud animal y el medio ambiente. De la relación contemporánea entre humanos y animales en su entorno circundante, surgen enfermedades, incluidas las zoonosis transmitidas de los animales al hombre. Teniendo en cuenta la leptospirosis, una enfermedad zoonótica, infecciosa, febril, aguda o crónica de etiología bacteriana cuya propagación está asociada con factores ambientales, pretendemos discutir, contextualizar y criticar, además de la necesidad de adaptar la infraestructura de las ciudades para sostener de la relación completa entre humanos y animales a la luz del concepto de Una Única Salud, 
medidas profilácticas como la vacunación contra la leptospirosis canina, teniendo en cuenta las pautas actuales.

Palabras clave: leptospirosis, vacunación canina, Salud Única

\section{Introdução}

A partir do final do século XIX, o conceito de Saúde Única (One Health) tem atraído atenção de pesquisadores, profissionais da saúde, economistas e ambientalistas, que apresentaram a necessidade de integração tanto do setor público como do privado para a conscientização de mudanças de atitude que refletem diretamente na vida dos seres humanos. Resumidamente, o conceito baseia-se na consciência das principais oportunidades que existem para proteger a saúde pública através de políticas destinadas a prevenir e controlar patógenos ao nível das populações animais, considerando a interface entre humanos, animais e o meio ambiente (Gibbs \& Anderson, 2009).

Dentre as doenças que são emergentes das relações contemporâneas entre o ser humano, os animais e o ambiente que os circundam estão as zoonoses, que, segundo Acha \& Szyfres (1986), correspondem às enfermidades que são transmissíveis entre os animais vertebrados e o homem. Nesse sentido, conforme Scaini et al. (2003), o estreitamento existente entre os animais de companhia e as pessoas, com o consequente aumento progressivo do número destes animais, incluindo ambientes de lazer e públicos, aumentam o risco potencial de infecção.

Uma zoonose característica de países tropicais e subtropicais, onde a onda de calor e a incidência de chuvas, especialmente no verão, favorecem a sua emergência, é a leptospirose, uma enfermidade infecciosa febril aguda ou crônica, de etiologia bacteriana, causada por espiroquetídeos do gênero Leptospira (Segurado et al., 2016).

Nesse sentido, o presente artigo busca discutir, contextualizar e criticar, além de propor adequação da infraestrutura das cidades na promoção das condições necessárias para sustentar o pleno relacionamento entre os seres humanos e os animais à luz da Saúde Única, medidas profiláticas como a vacinação canina contra a leptospirose, levando-se em conta as atuais diretrizes.

\section{Material e métodos}

Foi realizada uma revisão bibliográfica sobre o tema através de textos e artigos, seja de livros ou de revistas acadêmicas científicas on line ou impressas, abrangendo um panorama histórico da Saúde Única a partir de seu conceito, enfatizando as zoonoses. Com relação a leptospirose, é classificada entre uma das Doenças Relacionadas ao Saneamento Ambiental Inadequado (DRSAI), o foco da pesquisa bibliográfica foi realizado em literaturas que associaram seres humanos e cães. Para a realização da discussão entre a vacinação canina e Leptospirose, o texto-base utilizado foi desenvolvido pela Associação Veterinária Mundial de Pequenos Animais (WSAVA) no seu documento Diretrizes para a Vacinação de Cães e Gatos (Day et al., 2016).

\section{Saúde Única e zoonoses: Histórico e conceitos}

O conceito de Saúde Única (One Health) tal qual entendemos hoje provém da medicina clássica na Antiguidade, que tem em Hipócrates, considerado o "pai da medicina", o principal expoente e um dos criadores das ciências médicas. Seu legado, sobretudo na obra Sobre os Ares, as Águas e os Lugares, na defesa da saúde pública interligada às questões ambientais, especialmente no que diz respeito a um ambiente saudável, fez com que as ideias evoluíssem ao longo do tempo para termos o conceito de Saúde Única tal como é conhecido (Cairus, 2005).

Conforme Barret (2000), a consideração da questão geográfica no que diz respeito ao desencadeamento de doenças fez surgir uma nova visão intelectual da medicina que até então não fora explorada, a visão que associa as condições de saúde das populações com o meio ambiente. A importância que a obra teve para a evolução dos pensamentos posteriores foi enfatizada por Rosen (1958) no sentido de que a obra de Hipócrates se constitui no primeiro trabalho em caráter sistemático a expor uma relação de causalidade entre fatores de caráter ambiental e as doenças, que foi ao longo de mais de dois mil anos a base para a epidemiologia. 
As ideias lançadas por Hipócrates evoluíram até aos anos mais recentes. A associação entre os seres humanos e o ambiente ganhariam mais um integrante, os animais. Já no século XIX, por exemplo, o patologista alemão Rudolf Virchow afirmava que não existem divisórias no que concerne aos animais e a medicina humana. Nesse sentido, o termo zoonose foi cunhado por ele, termo esse que representa a doença ou infecção que é transmitida ao homem por intermédio dos animais. Além de Virchow, destacase neste cenário William Osler, médico contemporâneo a Virchow, muitas vezes conhecido como "pai da medicina moderna" que lançou as bases da hoje conhecida patologia veterinária em sua obra The Relations of Animals to Man (Almada \& Britto, 2019).

No século XX, o lançamento da obra intitulada Veterinary Medicine and Human Health, escrita em 1984 pelo veterinário Calvin Schwabe, lançou as bases da Saúde Única tais como se apresentam atualmente por intermédio do termo até então criado como One Medicine, ou Medicina Única. Nesta obra, foi de grande importância à discussão e reforço da união entre a saúde humana, animal e do meio ambiente (Bio em foco, 2019).

As interações entre seres humanos e animais acontecem em diversos ambientes e de diferentes maneiras e podem ser responsáveis pela transmissão de zoonoses. De fato, os seres humanos ao longo de sua história sempre tiveram com os animais uma relação de dependência, seja esta relacionada a necessidade de obtenção de alimento, de transporte, trabalho e até mesmo de companhia (Waldman, 2013). Em defesa a esta relação de dependência, Rapport et al. (1998 e 1999), Forget \& Lebel (2001) e Lebel (2002) defendem a ideia de que o desenvolvimento sustentável depende do mutualismo entre a saúde e o bem-estar de seres humanos, animais e ecossistemas nos quais coexistem. O que se discute reside no fato de que dessa estreita relação com os animais podem resultar em transmissão para os seres humanos de doenças infecciosas causadas por vírus, bactérias e outros parasitas (Seimenis, 2008).

Segundo Karesh et al (2012), entre os principais fatores que estão associados a emergências de epidemias ao longo do século XXI estão: a livre e ampla circulação de pessoas, animais, mercadorias e ideias, a capacidade de transporte em massa, a destruição de ecossistemas que acabam por aproximar patógenos desconhecidos de populações sensíveis, a intensificação da produção de alimentos sob a forma de monocultura, o alto processamento de circulação de alimentos com matéria-prima complexa e de origem variada, além da pressão humana que é provocada pelo excesso de população em um determinado local. Estes fatores associados explicam de certa maneira porque as enfermidades zoonóticas vêm apresentando cada vez mais importância no cenário mundial. No passado, o relativo distanciamento entre os povos, a baixa população e meios de transporte precários e limitados eram importantes agentes de quebra da cadeia de transmissão de doenças.

\section{Leptospirose canina, vacinação e diretrizes}

Partindo da definição de Segurado et al. (2016), a leptospirose é uma enfermidade zoonótica infecciosa febril aguda ou crônica, de etiologia bacteriana, causada por espiroquetídeos do gênero Leptospira, composto por cerca de 250 tipos de sorovariedades, sendo os principais: as Leptospiras icterohaemorrhagiae e a canicola (Langoni, 1999; Britto et al., 2018). Nos seres humanos, o ciclo da doença ocorre pelo contato direto da pele e mucosas com o ambiente contaminado pela urina dos animais reservatórios, sendo o principal composto por roedores (Rattus norvegicus), além de outros animais, como o cão, bovino e suíno. Do ponto de vista epidemiológico, é importante ressaltar a exposição acidental que existe em grandes centros urbanos, onde há maior incidência de enchentes e inundações, que contribuem para a propagação da doença. Conforme Faine (2000) e Levett (2001), são bactérias obrigatoriamente aeróbias e sua persistência no ambiente, quando não estão em estado de parasitismo, se dá na presença de umidade e temperatura que varia entre 28 a $32^{\circ} \mathrm{C}$ e de um $\mathrm{pH}$ neutro ou levemente alcalino, que varia em torno de 7,2 a 7,6.

De acordo com Faine et al. (1999), a doença nos cães pode se manifestar de forma subclínica ou clínica, podendo evoluir de maneira aguda ou crônica. Semelhante aos roedores, os cães quando infectados também podem eliminar o agente pela urina, sendo do mesmo modo propagadores da doença e fator de risco para o homem. As manifestações clínicas podem variar de acordo com o sorovar causador, sendo para o grupo icterohaemorrhagiae a icterícia o principal sintoma apresentado e para o grupo canicola a emese, diarreia, ulcerações na cavidade oral e necrose da língua aparecem como principais sintomas. A infecção também pode ser não aparente. No que se refere à capacidade para cães 
domésticos atuarem como reservatório da leptospirose, Vinetz (2001) e Levett (2001) apontam que tal capacidade existe nos mais variados ambientes que são ocupados pelo homem. Dessa forma, dado seu potencial reservatório, seu consequente papel na epidemiologia da leptospirose nas cidades não deve ser negligenciado.

Para Brown \& Prescott (2008) e Batista et al. (2005), é grande a importância do cão na transmissão da leptospirose ao homem, principalmente pelo fato de que a leptospira pode se manter por longos períodos nos rins, sendo possível eliminá-las pela urina sem qualquer apresentação de sinal clínico ou até mesmo pela consequente melhora clínica. Além disso, é destacado o seu papel como sentinela no sentido de detecção da presença de leptospirose no ambiente ao qual está inserido e por serem primordiais para o entendimento da epidemiologia da doença (Oliveira, 2010). De maneira geral, o diagnóstico baseia-se pelo histórico clínico, exame físico, manifestações clínicas e exames laboratoriais, como hemograma, bioquímica sérica e urinálise. O diagnóstico confirmatório ocorre pelo isolamento do agente através da hemocultura e urocultura e pela sorologia pareada. Segundo recomendação da Organização Mundial da Saúde (OMS), a prova para o diagnóstico definitivo é a soroaglutinação microscópica, na qual os anticorpos formados são direcionados contra o sorovar específico (Hagiwara et al, 2004).

Mundialmente, a imunoprofilaxia ocorre apenas contra os sorovares mais prevalentes, como os sorovares icterohaemorrhagiae e canicola. O estudo de Hagiwara et al. (2004) aponta que a imunidade dada aos cães pela vacina não tem duração conhecida; porém, acredita-se que a imunidade fornecida pela mesma tenha duração curta, sendo recomendada dose de reforço a cada seis meses, principalmente para os cães que vivem altamente expostos ao risco da infecção, em especial nas regiões com carência de saneamento básico adequado e regiões com alta incidência de chuvas, propícias a enchentes e inundações. No entanto, conforme Lunn (2019) estudos já demonstraram que a duração da imunidade nos cães pode ser de pelo menos um ano. Ainda, segundo Hagiwara et al. (2004) um aspecto importante a ser considerado é o de que a vacina protege contra o desenvolvimento da doença, mas não previne contra a colonização do rim e a eliminação urinária das leptospiras quando ocorrer a infecção natural, embora Lunn (2019) considera que a vacinação pode atuar como redutora da colonização renal.

Um possível ciclo da leptospirose se refere à transmissão da doença do roedor ao cão e do cão ao homem (Figura 1). Neste ciclo, os roedores (reservatórios) eliminam a leptospira pela urina, contaminando o ambiente, o solo, a água e os alimentos. O cão pode, por sua vez, ser infectado e ao mesmo tempo pode ser fonte de infecção para a família o qual ele faz parte. Nesse sentido, conforme exposto em documento da Organização Mundial da Saúde (1967), a leptospirose canina pode ser encarada como um grave problema de caráter sanitário, não apenas no que diz respeito a gravidade que corresponde sua patogenia, mas também com relação ao seu potencial de contágio aos seres humanos, dada a proximidade que é estabelecida entre ambos. Desta forma, a vacinação do cão e as corretas condições sanitárias contribuem para evitar a proliferação da doença.

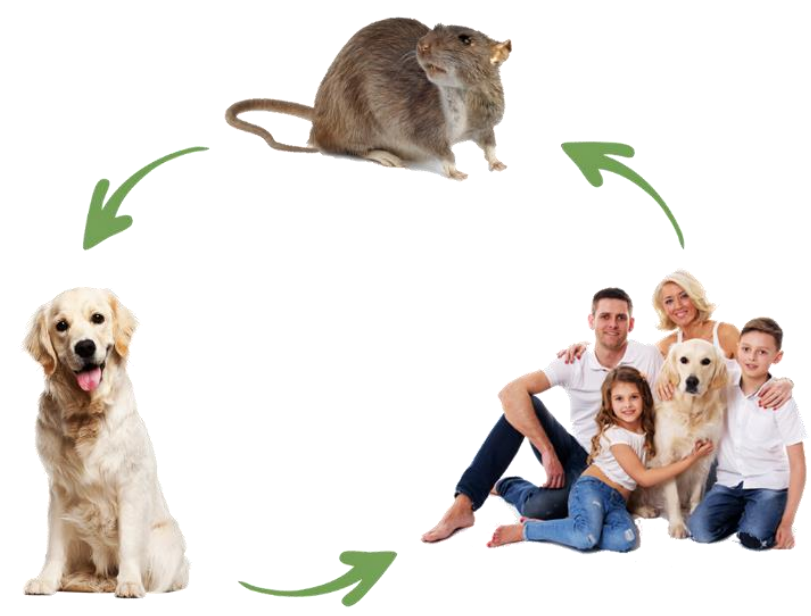

Figura 1. Ciclo da leptospirose considerando o cão como transmissor para o homem. Fonte: Autores 
A vacinação de cães contra a leptospirose é abordada pela Associação Veterinária Mundial de Pequenos Animais (WSAVA) no seu documento Diretrizes para a Vacinação de Cães e Gatos (Day et al., 2016). Neste documento, o Grupo de Diretrizes de Vacinação (VGG) reuniu-se de maneira a desenvolver diretrizes para a vacinação de cães que tivesse uma aplicação global. Porém, um ponto relevante no documento é que este grupo considera que os cuidados com os cães estão sujeitos a variação na prática e nos aspectos econômicos associados no mundo inteiro, e que, portanto, as recomendações de vacinação que são aplicáveis a países desenvolvidos podem não ter igual contrapartida em países em desenvolvimento. No que diz respeito à vacinação, a WSAVA apresenta em seu documento um panorama no qual estabelece o conteúdo da vacina bem como sua aplicação inicial nos primeiros meses de vida do filhote e do cão adulto bem como a recomendação da revacinação e demais comentários. Com relação ao seu conteúdo, a diretriz é que apresente a espécie Leptospira interrogans representada pelos sorogrupos canicola e icterohaemorrhagiae, sendo a bacterina inativada. A dose inicial deve ser aplicada aos filhotes a partir de 8 semanas de idade ou mais, sendo necessária uma segunda dose de duas a quatro semanas depois. Para os cães adultos, a recomendação é de duas doses com um intervalo de duas a quatro semanas, com revacinação anual tanto para os filhotes quanto os cães adultos. Por fim, a WSAVA considera a vacinação contra a leptospirose como não essencial, porém reconhece que é impossível de se produzir um conjunto de diretrizes que sejam igualmente aplicáveis a cada nação membro da Associação.

Além da recomendação quanto ao seu conteúdo e cronograma, o documento deixa claro que os veterinários devem se sentir à vontade para vacinar os cães de acordo com as diretrizes definidas, mas abre margem a possibilidade de flexibilização da prática com as recomendações locais quando forem disponíveis. Assim, embora exista uma associação internacional que defina a vacina contra a leptospirose como não essencial aos cães, o contexto brasileiro deve ser considerado, pois, de acordo com o próprio documento produzido pela WSAVA, existem vastas diferenças entre os países e regiões geográficas com respeito à presença/ausência de doenças infecciosas ou sua prevalência, disponibilidade do produto vacinal, populações de cães e gatos que têm donos em contraste com os que vagueiam livremente, e posição econômica e social da clínica e dos clientes, o que suporta a ideia da vacinação contra a leptospirose um fator relevante para a diminuição da incidência da doença em cães (Day et al., $\underline{2016}$.

Nos trabalhos de Querino et al. (2003) e Prescott et al. (2002) a constatação de alteração no perfil sorológico em cães está associado ao sucesso que a prática de vacinação nos cães têm trazido, sobretudo na vacinação que contém os sorovares Canicola e Icterohaemorrhagiae. Jaszczerski (2005) e Castro et al. (2011) também defendem a ideia de que a vacinação dos animais susceptíveis se mostra como uma forma bastante eficiente para o controle da doença nos mesmos e, em última instância, nos seres humanos. Soma-se a isto o fato de que as melhorias nas condições de moradia, provendo as cidades de infraestrutura devida de redes de esgoto e drenagem de áreas alagadas, além de um sistema eficiente de coleta seletiva de lixo são importantes medidas para serem adotadas visado a diminuição da leptospirose no ambiente.

\section{Epidemiologia nos seres humanos}

No estudo de Ko et al (1999), cujo objetivo foi traçar um perfil da doença nos humanos no Brasil, as regiões com maior incidência de casos de leptospirose são a Sul e a Sudeste. Entretanto, surtos de leptospirose têm sido também detectados nas regiões Norte e Nordeste do Brasil desde a década de 1980. A região Sul do país também não passa isenta de casos da doença, pois em áreas rurais existem casos de populações que são acometidas pela doença, com destaque para agricultores que trabalham em áreas alagadas, conforme exposto por um estudo desenvolvido pelo Ministério da Saúde/Secretaria de Vigilância em Saúde em 2008

Desde o início do século XXI, os casos de leptospirose no Brasil (Figura 2) são de, em média, 3.698 casos, com picos que chegam a quase 5.000 casos. Desde o ano 2000, em 9 anos (que representa a metade do período em questão) o número de ocorrências de leptospirose no país foi superior à média do período, sendo o ano de 2011 o que mais apresentou casos confirmados, em um total de 4.874. Além disso, em 3 anos consecutivos (2013, 2014 e 2015) o número de casos confirmados de leptospirose foram superiores à média do período e ao mesmo tempo superiores a 4.000 casos. Ao longo desse período, desconsiderando-se os dois últimos anos (que apresentaram números bem inferiores aos 
registrados), não parece haver tendência de aumento muito menos de queda no número de casos de leptospirose no país, o que indica, de certa maneira, a necessidade de políticas públicas para o combate da doença, dada a sua relativa estabilidade.

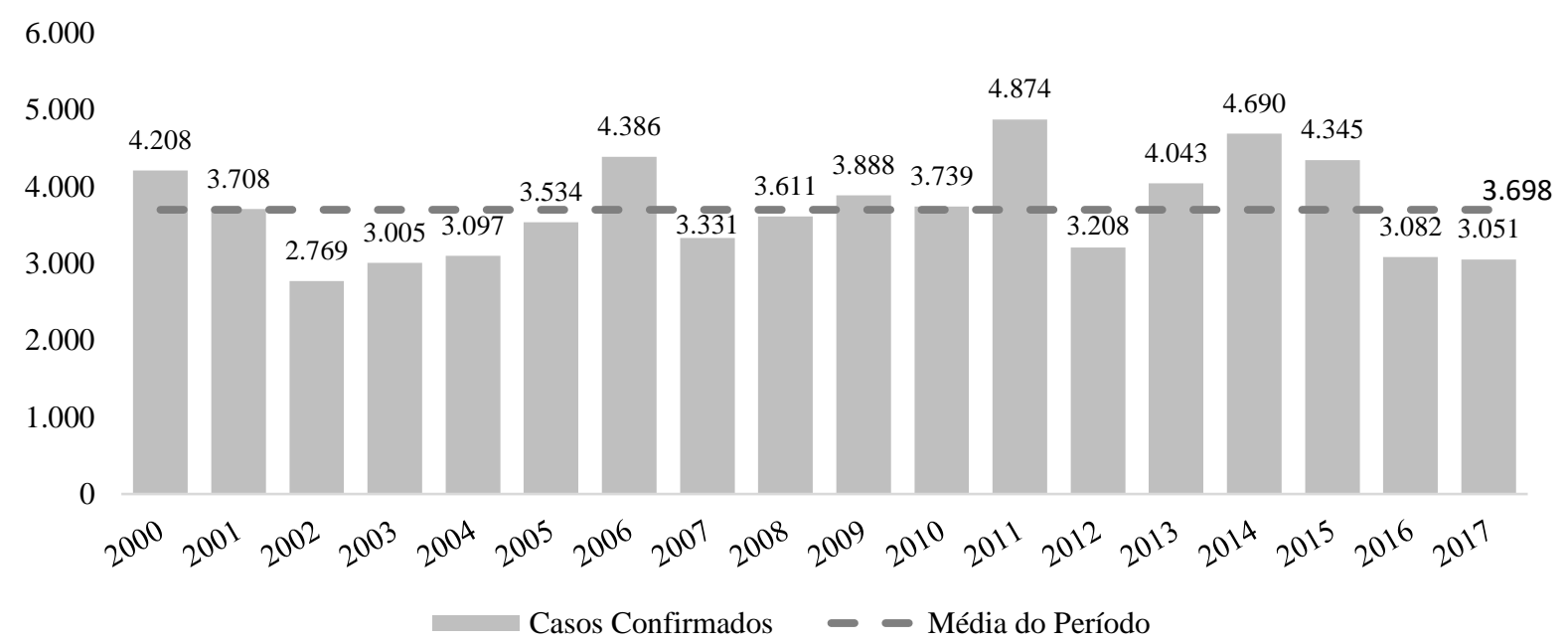

Figura 2. Casos de leptospirose no Brasil (2000 - 2017). Fonte: Ministério da Saúde/SVS - Sistema de Informação de Agravos de Notificação - Sinan Net (2019).

\section{Conclusões}

Dada a existente relação direta entre saúde humana e animal e o meio ambiente que os circundam, a leptospirose é um exemplo de consequência desta relação. Negligenciar esta enfermidade e as consequências que ela pode trazer nesta tríplice relação vai contra os princípios determinados pela Saúde Única, que defendem a harmonia destes três elementos.

Entender a necessidade da vacinação contra a leptospirose deve ser ponto inicial, levando-se em conta as características da bactéria, do ambiente ao qual o animal reservatório está inserido, além do relacionamento com o ser humano, respeitando o tipo de vacina a ser aplicada. A diretriz recomendada pela WSAVA considera que, embora ela não seja de caráter essencial, sua aplicação está condicionada a áreas geográficas com potencial de exposição aos cães, sobretudo as regiões de clima tropical como o Brasil.

Desta forma, espera-se que, observada as atuais condições sanitárias do país e a persistente incidência de leptospirose, a necessidade de vacinação dos cães deve surgir, da mesma forma que a necessidade de políticas públicas visando melhores condições de saneamento e infraestrutura urbana, como fator primordial para a diminuição da incidência da doença.

\section{Referências bibliográficas}

Acha, P. N. \& Szyfres, B. (1986). Zoonosis y enfermidades transmisibles comunes al hombre y animales. Washington: Organization Panamericana de la Salud.

Almada, G. L. \& Britto, S. G. (2019). Um mundo, uma saúde: a importância do médico veterinário na Saúde Única. Disponível em: <http://www.crmves.org.br/comunicacao/ ler/304>. Acesso em: 17 de jun. de 2018.

Bio em Foco. (2019). One Health: Você conhece o conceito de saúde única? Disponível em: <http://bioemfoco. com.br/noticia/one-health-conceito-saude-unica/>. Acesso em: 13 de jun. de 2019.

Barret, F. (2000). Disease and geography: the history of an idea. York University, Toronto.

Batista, C. S. A., Alves, C. J., Azevedo, S. S., Vaconcellos, S. A., Clementino, I. J., Lima, F. S. Neto, J. O A. (2005). Soroprevalência e fatores de risco para a leptospirose em cães de Campina Grande, Paraíba. Arquivo Brasileiro de Medicina Veterinária e Zootecnia, v.57, supl. 2, p.179-185.

Brito, T., Silva, A. M. G. \& Abreu, P. A. E. (2018). Pathology and pathogenesis of human leptospirosis: a commented review. Revista do Instituto de Medicina Tropical de São Paulo, 60, e.23. 
Brown, K. \& Prescott, J. (2008). Leptospirosis in the family dogs: a public health perspective. Canadian Medical Association Journal, 178:399-401.

Cairus, H. F. Ares, águas e lugares. In: Cairus, H. F., Ribeiro J. R., W.A. (2005) Textos hipocráticos: o doente, o médico e a doença. Rio de Janeiro: Editora FIOCRUZ. História e Saúde collection, p. 91-129.

Castro, J. R., Salaberry, S. R. S., Lima-Ribeiro, A. M. C. (2011). Sorovares de Leptospira spp. predominantes em exames sorológicos de caninos e humanos no município de Uberlândia, Estado de Minas Gerais. Revista da Sociedade Brasileira de Medicina Tropical, 44(2):217-222.

Day, M. J., Horzinek, M. C., Schultz, R. D. \& Squires, R. A. (2016). Diretrizes para a vacinação de cães e gatos. Journal of Small Animal Practice, 57.

Faine, S., Adler, B., Bolin, C. \& Perolat, P. (1999). Leptospira and leptospirosis. 2. ed. Melbourne: Medisci. 272p.

Faine, S. (2000). Guidelines for control of leptospirosis. World Health Organization, n.67.

Forget, G. \& Lebel, J. (2001). An ecosystem approach to human health. International Journal Occupation Environment and Health, 7:S3-38.

Gibbs, E. P. J. \& Anderson, T. C. (2009). One World - One Health and the global challenge of epidemic diseases of viral etiology. Veterinaria Italiana, 45(1):35-44.

Hagiwara, M. K., Lustosa, M. \& Kogika, M. M. (2004). Leptospirose canina. Veterinary News, 11, 67.

Jaszczerski, D. C. F. C. Cinética da resposta imune humoral em cães imunizados com Leptospira interrogans sorovares icterohaemorragiae, canicola, pomona e grippotyphosa. Dissertação Mestrado. Universidade Federal do Paraná, Curitiba; 2005. 82p.

Karesh, W. B., Dobson, A., Lloyd-Smith, J. O., Lubroth, J., Dixon, M. A., Bennett, M., Aldrich, S., Harrington, T., Formenty, P., Loh, E. H., Machalaba, C. C., Thomas, M. J. \& Heymann, D. L. (2012). Ecology of zoonoses: natural and unnatural diseases. Lancet, 380:1936-45.

Ko, A. I. Reis, M. G., Dourado, C. M. R., Johnson Júnior, W. D. \& Riley, L. W. (1999). Urban epidemic of severe leptospirosis in Brazil. Lancet, 354:820-825.

Langoni, H. (1999). Leptospirose: aspectos de saúde animal e saúde pública. Revista Educação Continental, 2, 52.

Lebel, J. (2002). Health: An Ecosystem Approach. Ottawa. Canadá.

Levett, P. N. (2001). Leptospirosis. Clinical Microbiology Reviews, 14:296-326.

Lunn, K. T. (2019). Leptospirosis in Dogs. MSD Manual - Veterinary Manual, 2019. Disponível em: $<$ https://www.msdvetmanual.com/generalized-conditions/leptospirosis/leptospirosis-in-dogs>. Acesso em: 05 de set. de 2019.

Ministério da Saúde/Secretaria de Vigilância em Saúde (2008). Investigação de surto de leptospirose em Várzea Alegre-CE, 2008. Boletim Eletrônico Epidemiológico, a. 8, n. 20, 2008. Disponível em: <www.saude.gov.br/images/pdf/2014/junho/25/Ano08-n20-surto-leptospirose-ce-completo.pdf>. Acesso em: 28 de ago. de 2019

Ministério da Saúde/SVS - SVS - Sistema de Informação de Agravos de Notificação - Sinan Net (2019). Disponível em: 〈http://portalsinan.saude.gov.br/dados-epidemiologicos-sinan〉. Acesso em: 7 de set. de 2019.

Oliveira, S. T. (2010). Leptospirose canina: dados clínicos, laboratoriais e terapêuticos em cães naturalmente infectados. 89 f. Tese (Doutorado em Ciências Veterinárias) - Faculdade de Veterinária. Universidade Federal do Rio Grande do Sul, Porto Alegre.

Organização Mundial Da Saúde. (1967). Current problems in leptospirosis research. Report of a who expert group. Technic Report Service, 380:1-32.

Prescott, J. F., McEwen., B., Taylor, J., Woods, J. Paul., Abrams-Ogg, A. \& Wilcock, B. (2002). Resurgence of leptospirosis in dogs in Ontario: recent findings. Canadian Veterinary Journal, 43(12):955-961. 
Querino, A. M., Delbem, Á. C. B., Oliveira, R. C., Silva, F. G., Müller, E. E., Freire, R. L. \& Freitas, J. C. (2003). Fatores de risco associados a leptospirose em cães do município de Londrina-PR. Semina: Ciências Agrárias, 24(1):27-34.

Rapport, D. (1998). Ecosystem Health. Oxford.

Rapport, D. J., Buckingam, D., Costanza, R., Böhm, G., Jr, J. C., Karr, J. R., Levins, R., Nielsen., N. O., Kruijf, H. A. M., McMichael,, A. J. \& Whitford, W. G. (1999). Ecosystem health: the concept, the ISEH, and the important tasks ahead. Ecosystem Health, 2:82-90.

Rosen, G. (1958). A history of public health. Nova Iorque: MD Publications, 551p.

Scaini. C. J., Toledo, R. N., Lovantel, R., Toledo, R. N. De., Lovatel, R. M., Dionello, M. A., Gatti, F. A. A. Dos., Susin, L. R. O. \& Signorini, V. R. M. (2003). Contaminação ambiental por ovos e larvas de helmintos em fezes de cães na área central do Balneário Cassino, Rio Grande do Sul. Revista da Sociedade Brasileira de Medicina Tropical, 36(5):617-619.

Segurado, A. C., Cassenote, A. J. \& Luna, E. A. (2016). Saúde nas metrópoles - Doenças infecciosas. Estudos Avançados, 30, 86.

Seimenis, A. M. (2008). The spread of zoonoses and other infectious diseases through the international trade of animals and animal products. Veterinaria Italiana, 44:591-599.

Vinetz, J. M. (2001). Leptospirosis. Current Opinion in Infectious Diseases, 14:527-538.

Waldman, M. (2013). Relação entre homens e animais. Petlove. Disponível em: < https://www.petlove.com.br/dicas/relacao-entre-homens-e-animais>. Acesso em: 17 de jul. de 2019.

Recebido: 19 de outubro, 2019.

Aprovado: 18 de novembro, 2019.

Publicado: 22 de março, 2020.

Licenciamento: Este artigo é publicado na modalidade Acesso Aberto sob a licença Creative Commons Atribuição 4.0 (CC-BY 4.0), a qual permite uso irrestrito, distribuição, reprodução em qualquer meio, desde que o autor e a fonte sejam devidamente creditados 